\title{
SACD's Support of the Hyper-X Program
}

\author{
Jeffrey S. Robinson ${ }^{*}$ and John G. Martin ${ }^{\dagger}$ \\ NASA Langley Research Center, Hampton, VA 23681
}

\begin{abstract}
NASA's highly successful Hyper-X program demonstrated numerous hypersonic air-breathing vehicle related technologies including scramjet performance, advanced materials and hot structures, GN\&C, and integrated vehicle performance resulting in, for the first time ever, acceleration of a vehicle powered by a scramjet engine. The Systems Analysis and Concepts Directorate (SACD) at NASA's Langley Research Center played a major role in the integrated team providing critical support, analysis, and leadership to the Hyper-X Program throughout the program's entire life and were key to its ultimate success. Engineers in SACD's Vehicle Analysis Branch (VAB) were involved in all stages and aspects of the program, from conceptual design prior to contract award, through preliminary design and hardware development, and in to, during, and after each of the three flights. Working closely with other engineers at Langley and Dryden, as well as industry partners, roughly 20 members of SACD were involved throughout the evolution of the Hyper-X program in nearly all disciplines, including lead roles in several areas. Engineers from VAB led the aerodynamic database development, the propulsion database development, and the stage separation analysis and database development effort. Others played major roles in structures, aerothermal, GN\&C, trajectory analysis and flight simulation, as well as providing CFD support for aerodynamic, propulsion, and aerothermal analysis.
\end{abstract}

\section{$\underline{\text { Abbreviations }}$}

$\begin{array}{ll}\text { BET } & \text { Best Estimated Trajectory } \\ \text { CFD } & \text { Computational Fluid Dynamics } \\ \text { DFRC } & \text { Dryden Flight Research Center } \\ \text { GN\&C } & \text { Guidance, Navigation \& Control } \\ \text { HXFE } & \text { Hyper-X Flight Engine } \\ \text { HXLV } & \text { Hyper-X Launch Vehicle } \\ \text { HXRV } & \text { Hyper-X Research Vehicle } \\ \text { IDT } & \text { Integrated Design Team } \\ \text { LaRC } & \text { Langley Research Center } \\ \text { NASP } & \text { National AeroSpace Plane } \\ \text { OML } & \text { Outer Mold Line } \\ \text { POST } & \text { Program to Optimize Simulated } \\ & \text { Trajectories } \\ \text { RTF } & \text { Return to Flight } \\ \text { SACD } & \text { Systems Analysis and } \\ & \text { Concepts Directorate } \\ \text { VAB } & \text { Vehicle Analysis Branch }\end{array}$

\footnotetext{
${ }^{*}$ Aerospace Engineer, Vehicle Analysis Branch, M/S 451, Senior Member, AIAA
}

${ }^{\dagger}$ Aerospace Engineer, Vehicle Analysis Branch, M/S 451, Senior Member, AIAA 


\section{Introduction}

In 1996 NASA initiated the Hyper-X Program, a jointly conducted effort by the NASA Langley Research Center (LaRC) and the NASA Dryden Flight Research Center (DFRC), as part of an initiative to mature the technologies associated with hypersonic airbreathing propulsion ${ }^{1}$. Unlike its predecessor, the U.S. National Aero-Space Plane (NASP) program, Hyper-X was a very focused program offering an incremental approach to developing and demonstrating scramjet technologies. During the NASP program, attempts were made to develop and integrate many new, unproven technologies into a full-scale flight test vehicle. In hindsight, this was an overly ambitious goal that was both technically and programmatically unachievable, given the relative immaturity of the various technologies and the budgetary constraints of the time. By contrast, the primary focus of the Hyper-X program was the development and demonstration of critical scramjet engine technologies, using several small, relatively low cost, flight demonstrator vehicles. This philosophy was a direct outcome of NASA's "better, faster, cheaper" approach to flight projects and programs in general.

The primary goals of the Hyper-X program were to demonstrate and validate the technologies, the experimental techniques, and the computational methods and tools required to design and develop hypersonic aircraft with airframeintegrated dual-mode scramjet

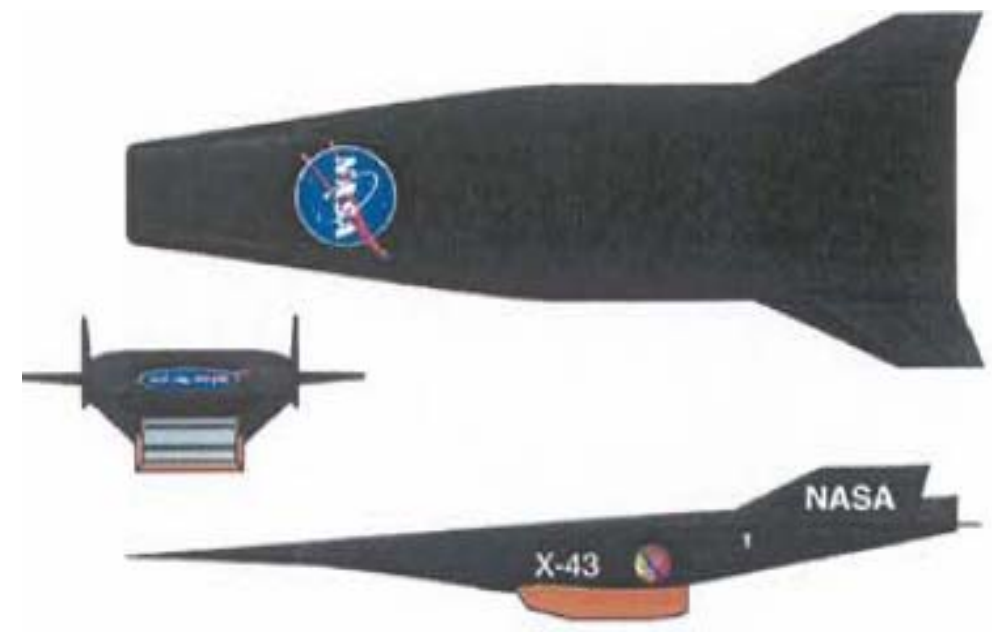

Figure 1. 3-view of Hyper-X Research Vehicle propulsion systems. Hypersonic airbreathing propulsion systems, studied in the laboratory environment for over 40 years, had never been flight tested on a complete airframe integrated vehicle configuration. Three Hyper-X flight test vehicles (Figure 1), the first two of which were to fly at Mach 7 and the third at Mach 10, would provide the first opportunity to obtain data on airframe integrated scramjet propulsion systems at true flight conditions.

Prior to contract award in 1997, systems analysis experts from VAB, working with their counterparts from McDonnell Douglas in St. Louis, performed the initial systems analysis studies that led to the Hyper-X vehicle design. Hyper-X gets its shape, or outer mold line (OML) design, from the Mach 10 Dual-Fuel Global-Reach vehicle ${ }^{2,3}$. VAB engineers were involved in developing the keel line, OML, baseline propulsion and aerodynamic databases, design loads, mechanical design, thermal analysis, vehicle performance, stage separation analysis, and basic system requirements, all of which became part of the government furnished items at the time of contract award in the spring of 1997. After the contract to finalize the design and build the three flight vehicles was awarded, engineers in VAB continued to support the program as the preliminary design evolved through membership in the program's Integrated Design Teams (IDTs). 


\section{Propulsion}

Support in the propulsion discipline included participation in engine redesigns and analyzing engine ground test data ${ }^{4,5}$. Effective utilization of scramjet engines requires careful integration with the air vehicle. This integration synergistically combines aerodynamic forces with propulsive cycle functions of the engine. Due to the highly integrated nature of the hypersonic vehicle design problem, the large flight envelope, and the large number of design variables, the use of a statistical design approach in design is effective. Modern Design-ofExperiments (MDOE) was used throughout the Hyper-X program, for both systems analysis and experimental testing.

One specific example was the flush wall injector design, which engineers from VAB were directly involved with. Independent parameters selected for this study included fuel injection angle, injector total pressure, fuel equivalence ratio, fuel split, injector to gap spacing, mach number, and combustor length. A test point matrix was defined for a minimum, nominal, and maximum value for each of the independent variables. This MDOE study used threedimensional CFD to solve the scramjet combustor reacting flow fields. Forebody and inlet CFD solutions provided initial conditions for the 3-D combustor CFD. A limited number of 2-D nozzle solution where performed, using the combustor solutions for inflow conditions, to characterize the nozzle performance.

Over a dozen responses were generated from the study including mixing efficiency, combustion efficiency, combustor total pressure recovery, nozzle coefficient, combustor static pressure, combustor Mach number, and other engine performance related parameters. Each of these responses was post processed from individual CFD solution data planes, or combustor cross-sections, or other CFD output files. Finally, regression equations were developed for each of the responses and were used to help guide the injector redesign.

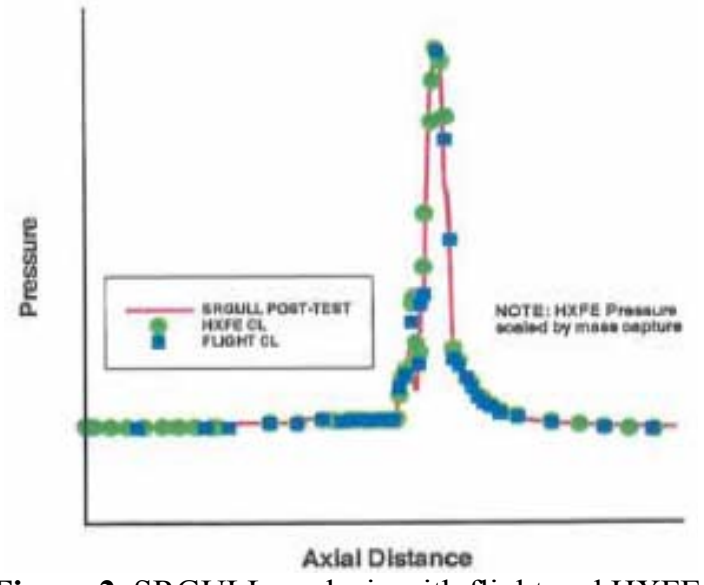

Figure 2. SRGULL analysis with flight and HXFE.

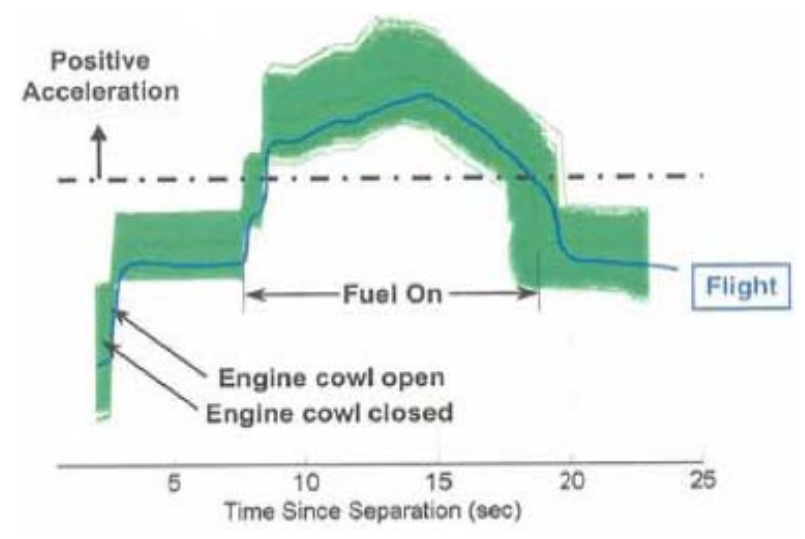

Figure 3. Mach 7 acceleration predictions.

VAB's propulsion engineer also had the primary responsibility of producing the official predicted engine performance databases for the Mach 7 flight experiment ${ }^{6}$. This database along with the Mach 7 engine conceptual design, ground test data analysis and post-flight data analysis were performed using an integrated engine performance analysis code called SRGULL. The database evolved with time due to the execution of the ground test program and CFD analysis efforts. The final pre-test version of the database derived its combustion efficiency from the Hyper-X Flight Engine (HXFE) ground tests but was also decremented to account for the 
expected reduced efficiency in flight for "clean" air. SRGULL results for the "on point" test condition are shown in Figure 2. Three flight Mach numbers, three angles of attack, four dynamic pressures, and six fuel equivalence ratios were included in the database and supplied to the X-43A simulation team who used the propulsion database in conjunction with other vehicle data to construct the vehicle control laws and fly simulated trajectories. These simulations were key to insuring a successful flight test.

In addition to the nominal engine performance predictions, a range of minimum and maximum expected values of engine axial force, normal force and pitching moment for each of the points in the database was also provided. Uncertainty values were chosen to try and capture the extremes of possible engine performance. These uncertainty values were necessary so that Monte Carlo analysis could be performed to assess potential flight test results and to stress the flight and engine control laws. Figure 3 shows the pre-flight expected acceleration during the engine experiment overlaid with actual flight data.

\section{Aerodynamic Database}

VAB's aerodynamics experts held prime responsibility for the development of the research vehicle's aerodynamic database. Coordinating and compiling data from thousands of wind tunnel runs in numerous facilities with the results from engineering predictive analyses and CFD calculations to generate the vehicle's aerodynamic database was a highly complex problem that was critical to flight success. The Hyper-X aerodynamic database ${ }^{7,8}$ was comprised of data which supported the mission through all phases of flight, as shown in Figure 4, beginning with the HXLV dispense from the B-52, the ascent of the HXLV to the test condition, the separation of the X-43A vehicle from the HXLV, the engine test including the powered and unpowered post test tare measurements, and the descent of the research vehicle to subsonic terminal conditions.

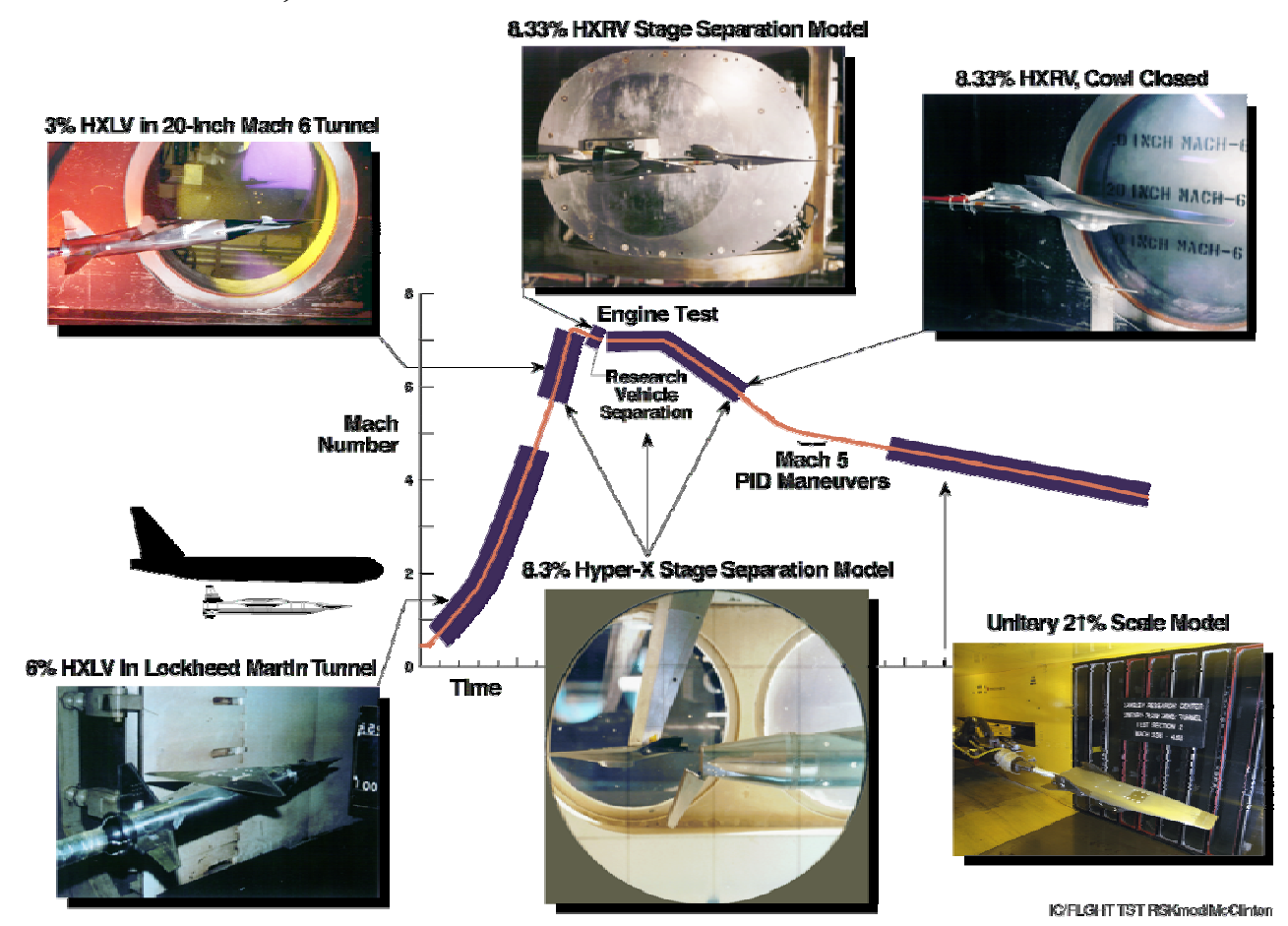

Figure 4. Snapshot of various wind tunnel tests, models, and facilities needed showing the regions of the Hyper-X flight profile that each test covered. 
The Orbital Sciences Corporation was responsible for development of the HXLV and all of its associated databases (though much of the data was generated in LaRC wind tunnels), while VAB engineers took the lead on developing the aerodynamic databases for the HXRV. The most complicated of these databases was by far the stage separation database. The X-43A stage separation from the HXLV, which occurred at the extreme environmental conditions associated with flights at Mach 7 and 10, and dynamic pressure of approximately 1000 psf, was a complicated dynamic event which had to be executed precisely so as not to upset the X-43A in a manner such that it could not obtain the steady, controlled flight conditions required to conduct the scramjet engine test.

A series of wind tunnel tests were conducted to characterize the aerodynamic forces and moments associated with this two body, mutual interference separation problem. Preliminary estimates of the aerodynamic interference effects were obtained by modifying a wind tunnel model of an early X-43A configuration to permit a non-symmetric HXLV conical adapter to be clamshell mounted directly on the model sting. Several screening tests conducted in the NASA Langley 20-inch Mach 6 and 31-inch Mach 10 wind tunnels provided a rapid initial assessment, but permitted only axial separation between the X-43A model and adapter (no relative vertical or lateral translation and no relative angular displacement), and measured only the effect of the adapter on the research vehicle aerodynamics (as opposed to the simultaneous mutual interference of the two bodies on each other).

Once the proof of concept had been defined, a high fidelity, $8.33 \%$ scale, multicomponent model, which included the entire HXLV configuration, was built and tested at the Arnold Engineering Development Center - von Karman Gas Dynamics Facility (AEDC-VKF) Tunnel B, at Mach 6 test conditions ${ }^{9,10}$. Six component force and moment data were obtained for both the X-43A and the HXLV booster + adapter combination in close proximity to each other.

Early in the program, initial wind tunnel screening tests were conducted to determine the basic X-43A airframe aerodynamics, including stability, control, and performance characteristics. These "quick look" tests were conducted using small scale, rapid fabrication models in the Langley 20-inch Mach 6 and 31-inch Mach 10 facilities, the Boeing (formerly McDonnell Douglas) - St. Louis Polysonic tunnel, and the Boeing North American subsonic tunnel. As the vehicle design matured, additional testing was conducted using larger, higher fidelity models, with very fine gradations in control surface increments.

Additional entries using the refined high fidelity models were made in the NASA Langley 16 -ft Transonic facility $(0.6<$ Mach $<1.2)$, Unitary Plan Wind Tunnel facility $(1.5<$ Mach < 4.6), the 20-inch Mach 6, and the 31 -inch Mach 10 tunnels, in order to fully bracket the anticipated flight envelope. Due to the relatively small scale of these aerodynamic force and moment wind tunnel models, inlet-open testing (unpowered or powered using a simulant gas technique) was not possible. Again, many of these models and facilities are seen in Figure 4.

A comprehensive CFD study was undertaken to provide estimates of the inlet-open unpowered and powered flight aerodynamic characteristics for the Mach 7 vehicles, including the effects of Mach number, angle-of-attack, and sideslip on the X-43A. A number of different CFD codes and tools were utilized to predict the airframe forces and moments associated with the inlet open flight conditions, including both unpowered and powered engine operation modes. These methods included CFD codes, both structured Euler and Navier-Stokes solvers, for external airframe analysis, and propulsion cycle analysis codes which model the scramjet combustion physics and flowpath processes. A sample of the resulting longitudinal aerodynamics is shown in Figure 5. 

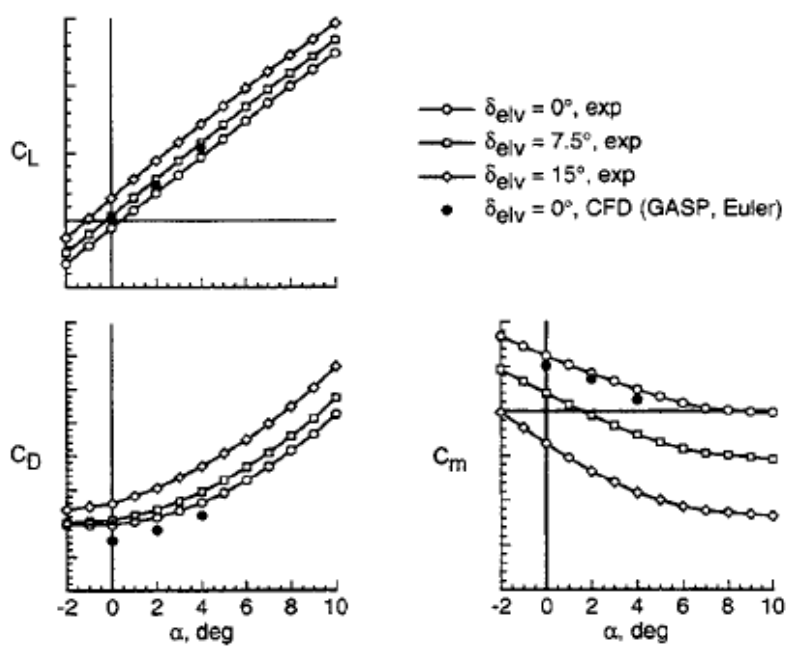

Figure 5. X-43A Mach 6 longitudinal aerodynamic characteristics.
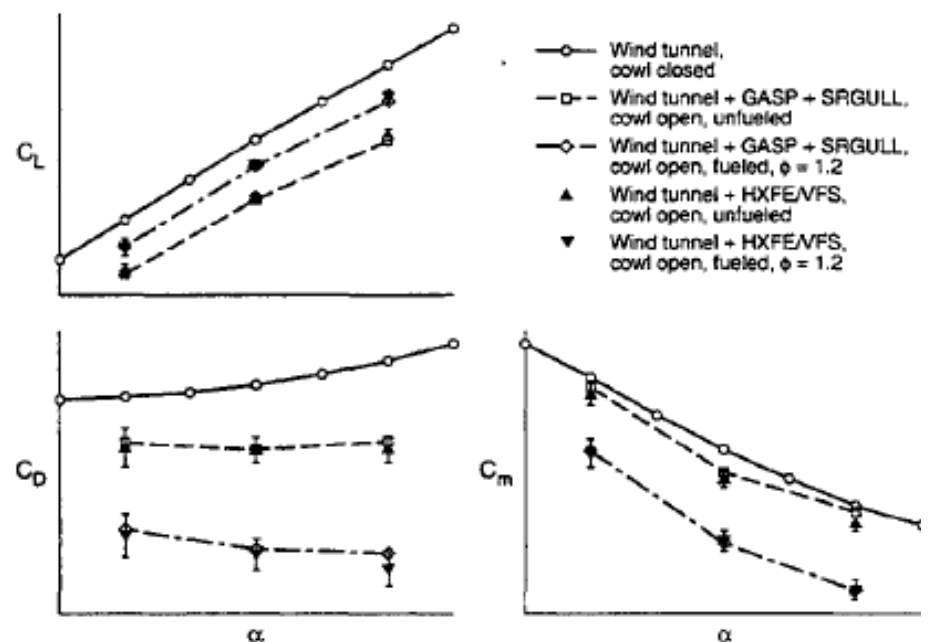

Figure 6. X-43A longitudinal forces and moments - inlet open unpowered and powered modes including validation results from the 8-ft HTT.

Effects of elevon position on the basic lateral-directional characteristics of the HXRV were investigated. At issue was the question of the effect of vehicle sideslip and the expanding propulsion plume acting over the vehicle aftbody, and whether or not the plume would tend to increase or decrease the configuration's basic lateral-directional stability characteristics. The effect of elevator position on the HXRV aileron control effectiveness was investigated, as were the effects of elevator position on the rudder effectiveness.

Engineers from SACD were involved at each stage of testing and were ultimately responsible for scaling, adjusting and combining all of the wind tunnel results, CFD analysis, and other information to develop a unified aerodynamic database for each of the HXRV flight phases. Some validation of the inlet closed + inlet open increments + fuel on increments methodology, as well as the accuracy of the data in each of those data sets, was found with results from the HXFE tests in LaRC's 8-ft High Temperature Tunnel. As shown in Figure 6, the buildup methodology and data agreed very well with the inlet open fueled and unfueled data from the HXFE tests.

\section{Aerothermal Analysis}

VAB's aerothermodynamics experts were heavily involved in the design and analysis of the research vehicle's hot structural components, namely the vehicle nose, all-moving horizontal control surfaces, and vertical tails ${ }^{11}$. VABs engineers developed a unique approach to quantifying and accounting for some extremely complex aerothermodynamic phenomena such gap heating, corner flows, shock impingement, and shock-shock interaction, all of which can cause significant increases in localized heating. Engineers helped identify critical material shortcomings that eventually led to design changes for the third flight vehicle (Mach 10).

As seen in Figure 7, the nose, horizontal tail, and vertical tail on the Hyper-X vehicle were all designed as hot structure components with no active cooling or additional thermal protection such as tiles. The nose and horizontal tails employed carbon-carbon leading edges while the vertical tails were constructed out of Haynes 230 alloy with Haynes leading edges for the Mach 7 flight and carbon-carbon leading edges for the Mach 10 flight. 


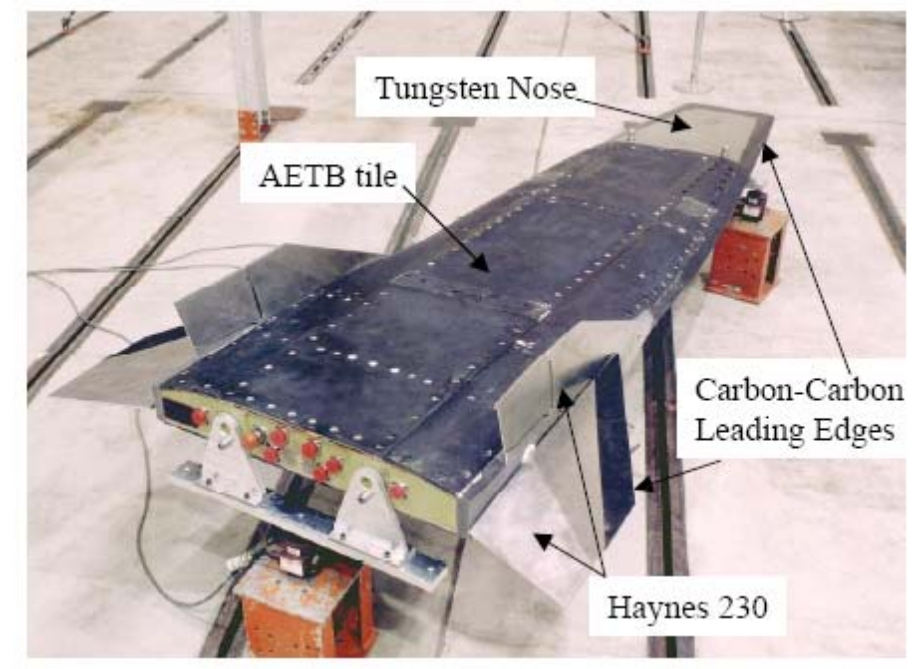

Figure 7. Hyper-X research vehicle showing hot structure components.
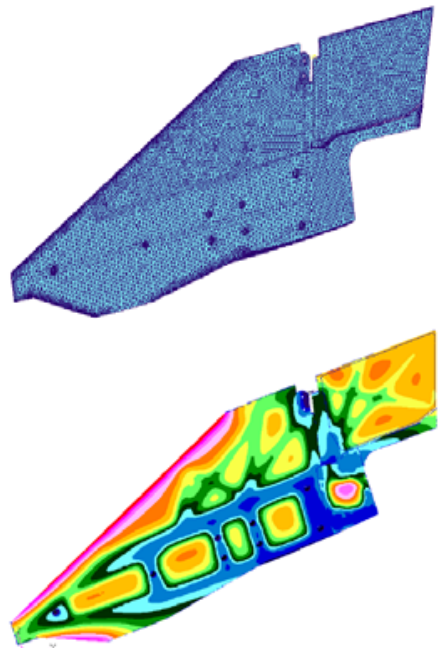

Figure 8. Finite element mesh model for vertical tail and predicted temperature distribution for Mach 7 flight.

The control surfaces on the HXRV, along with the vehicle nose, were subjected to significant aeroheating without the benefit of a thermal protection system and were therefore referred to as hot structures. The purpose of the aeroheating and thermal analysis process was to predict the probable heating loads on the hot structure components and the resultant temperatures. From these temperatures and gradients, a structural analysis could be performed which would demonstrate the deflections and stresses in the material. The temperature predictions would then be used to verify that all materials remained within their allowable temperature ranges.

To produce heat fluxes, the trajectory was discretized for local maxima and minima in the variables that impact heating. Doing so produces a piecewise linear representation of the trajectory. Variables of interest include Mach number, vehicle angle of attack, dynamic pressure, and control surface deflection. Using a variety of engineering level codes, validated by CFD, heat loads were computed at 20 discrete time steps along the 130-second preflight trajectory. 3-D maps of heat fluxes $(q)$ were generated for each of the hot structure components at each given time point in the trajectory. These heat fluxes were obviously dependent on the skin temperature of the component. Thus, after a solution was run for a given set of q maps, the temperature maps were provided back to the aerothermal codes, and new q maps based on the latest temperature prediction were run. Several (3-4) iteration loops were usually required for this cycle to come to closure. Closure was defined as when temperatures between solution sets were varying less than $10^{\circ} \mathrm{F}$. Figure 8 shows the finite element mesh model for the HXRV vertical tail as well as the predicted temperature distribution for one of the points in the Mach 7 flight profile.

A similar process was followed to analyze the flight data from the Mach 7 flight (and was performed for the Mach 10 flight). Heat loads and the associated thermal responses were produced at 27 points along the Best Estimated Trajectory (BET). The Mach 7 nose had a single thermocouple located on a butt line 0.50 inch off the vehicle centerline and at a fuselage station 0.5-0.7 inches aft of the leading edge. A comparison of the flight data and the postflight analysis results is shown in Figure 9 with two heating estimates believed to bracket the actual thermocouple location. Two thermocouples were installed in the Mach 10 carbon-carbon nose at 1.0 
inch and 1.5 inches aft of the physical nose and near the vehicle centerline. Figure 10 shows good agreement between flight data and preflight predictions made without applying uncertainty factors. The quality of the Mach 10 comparison is similar to that shown for the Mach 7 leading edge.

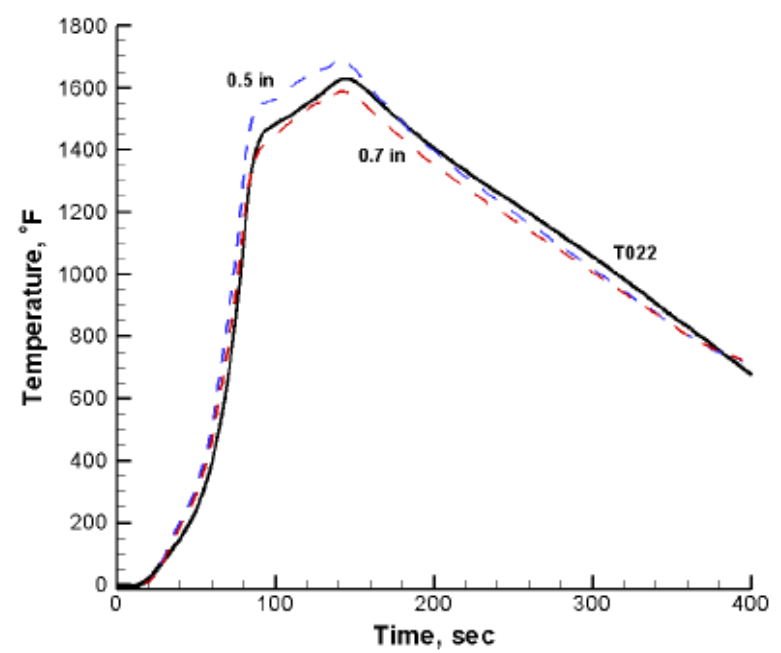

Figure 9. BET predicted temperature profiles for the vehicle nose for the Mach 7 flight with flight data overlaid.

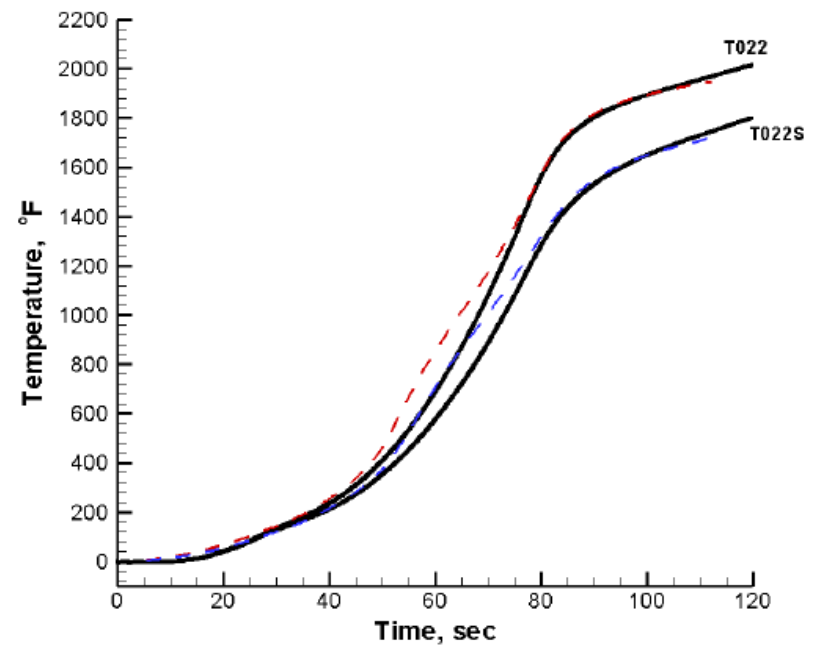

Figure 10. Preflight Mach 10 predicted nose temperatures with flight data.

\section{Stage Separation}

Engineers from VAB also led the entire stage separation effort ${ }^{12}$. As part of the baseline mission, the research vehicle was required to separate from Pegasus-derived rocket booster near the scramjet test condition. Such a separation of two non-axisymmetric vehicles, as shown in Figure 11, in a high Mach number, high dynamic pressure environment had never been done before. This was a huge task and a problem of such complexity, that it actually made making the scramjet work seem simple. Thousands upon thousands of wind tunnel runs measured the interference effects that the two bodies in close proximity had on each other. Tests were conducted to characterize separation mechanisms from which detailed models were built and incorporated into the simulation. Additional tests helped to evaluate event

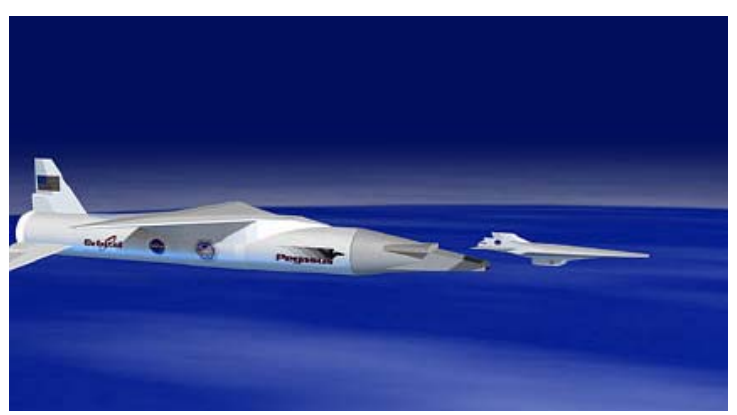

Figure 11. Depiction of X-43A stage separation. sequence timing.

A 15 degree-of-freedom (6-HXLV, 6-HXRV, 2-ejector pistons, 1-rotating drop jaw) simulation of the separation event was developed by VAB engineers and contractors, and hundreds of thousands of simulations were run to examine potential outcomes and to help determine the best flight controls approach. This tool, called SepSim, models all of the vehicle dynamics, separation mechanics, and aerodynamics for both vehicles and uses an industry standard simulation code called ADAMS to supply general multi-body equations of motion, simulation integration, and input/output capabilities. The SepSim team coded user subroutines for aerodynamic forces and moments, control system characteristics, atmosphere modeling, bolt 
and ejector piston characteristics, and HXLV and HXRV actuator characteristics. By definition, the separation event started when the command was given to blow the explosive bolts attaching the two vehicles and ended 2.5 seconds later when the HXRV had cleared the influence of the HXLV and had recovered to the desired state to begin the engine test.

Engineers used SepSim to help develop the control law strategy and feedback loop closure timing for the separation event. At the command to separate, the HXRV actually flew open loop with the horizontal control surfaces moving from their fixed zero degree deflection position to a set position (based on vehicle angle of attack) near what would be the trim position for the HXRV in free flight at that flight condition (cowl closed). Moving at the actuator rate limit, the horizontal control surfaces reached this deflection near the end of the piston push $(0.1$ seconds into separation). Feedback loops for the sideslip and roll rates were then faded in, followed closely by pitch rate. At the same time, the HXLV was commanded to a hard pitch down to minimize the risk of re-contact. Attitude feedback loops on the HXRV were then faded in, commanding roll and sideslip angles to zero degrees and angle of attack to the test point target of 2.5 degrees. All loops were closed and the HXRV was under full autonomous control, flying free of the HXLV's influence within $500 \mathrm{~ms}$ of the initiation of the separation event. All of this complex sequencing and timing was designed using the SepSim model that VAB engineers helped build.

In order to obtain a more comprehensive validation of SepSim, and thus satisfy one objective of the Return-To-Flight activity, VAB engineers developed an independent simulation of the Hyper-X stage separation using the Program to Optimize Simulated Trajectories (POST) ${ }^{13}$. Previous independent simulation validation efforts relied on SepSim to generate a "delta" force and moment model to account for aerodynamic interference effects during separation. This model was incorporated into the 6-DoF simulation DFRC had built to model the HXRV in free flight, and was then used to "validate" SepSim results. Recent enhancements to POST II allowed for the construction of a completely independent simulation that could validate the SepSim results and verify the numerous simulation models used to predict the flight behavior of both vehicles. Also, by utilizing software specialized for trajectory calculations, it was possible to develop a simulation that provided similar results as SepSim, but was simpler and more concise. As such, the POST II simulation took much less CPU time to execute than the higher fidelity SepSim which made it well suited for conducting trade studies and sensitivity analyses that required

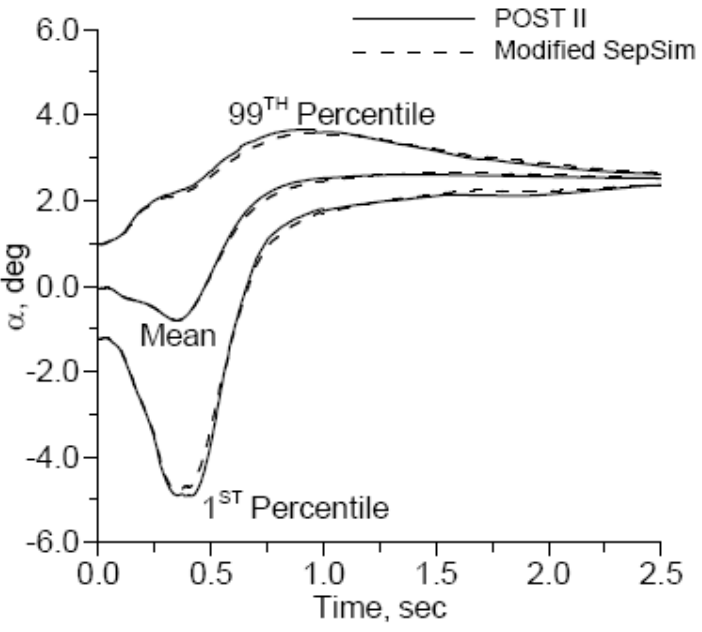

Figure 12. Comparison of angle of attack profile statistics from Monte Carlo analysis between SepSim and the POST II simulation. the running of numerous Monte Carlo cases, thus providing the project with an additional analysis tool. A comparison of the two simulation tools is shown in Figure 12.

VAB engineers also performed post-flight analysis of both the Mach 7 and Mach 10 flights, comparing flight performance to both simulation models and pre-flight Monte Carlo predictions ${ }^{14}$. Figure 13 shows a comparison of the axial acceleration expected during the piston push for the Mach 7 flight overlaid with the actual flight data. Good agreement indicated here and in other comparisons indicate that many of the components of the separation event were 
being modeled accurately. However, performance of the control system during the Mach 7 flight showed some lag in the system response to attain the desired angle of attack. This characteristic was traced to an under-prediction of $\mathrm{Cm}_{0}$. This effect was corrected for in the Mach 10 flight, and as shown in Figure 14, performance was well with the expected range.

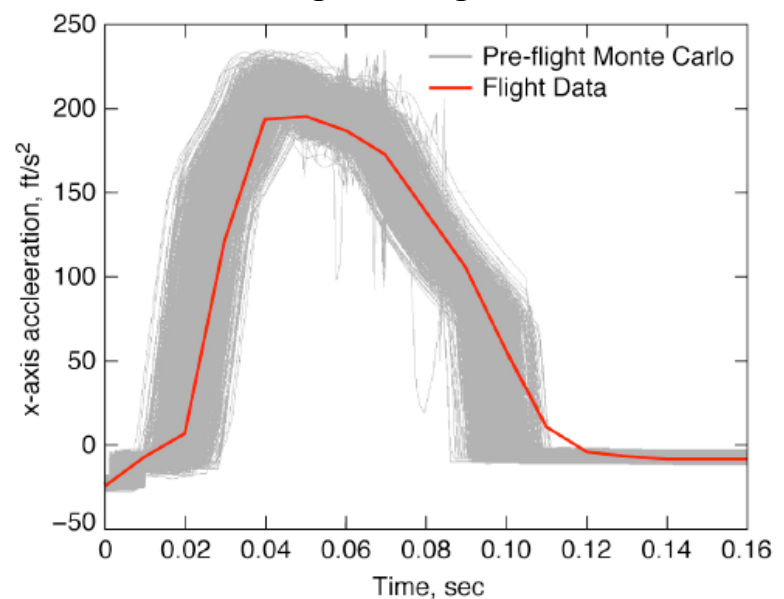

Figure 13. Axial acceleration profile during piston push for the Mach 7 flight. Flight data vs. pre-flight Monte Carlo.

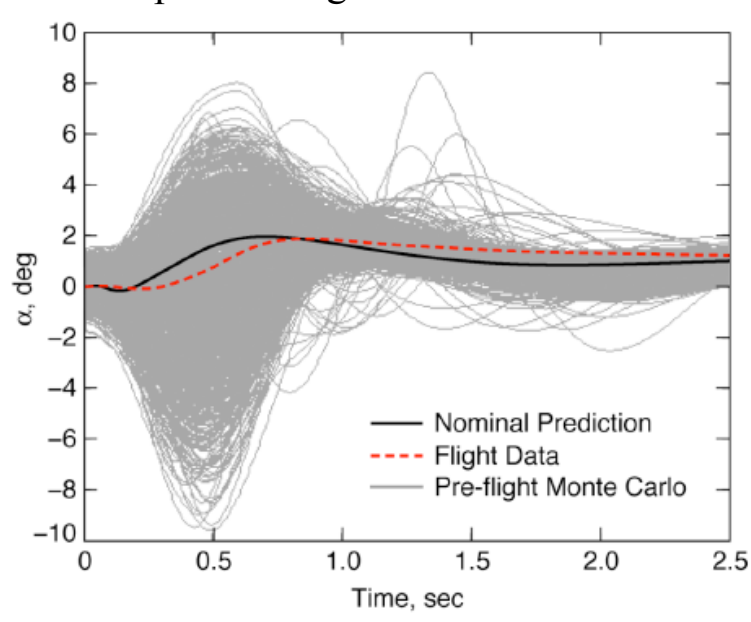

Figure 14. Comparison of Mach $10 \mathrm{HXRV}$ angle of attack time history during separation. Flight data vs. pre-flight Monte Carlo.

\section{Structures}

Structural engineers from VAB performed numerous critical tasks over the life of the program including dynamic analysis of the launch stack ${ }^{15}$. Their analysis identified critical problems with longitudinal and lateral bending frequencies. VAB's engineers, through exhaustive analysis, suggested design changes which, when implemented by the program, proved crucial to raising the launch stack frequencies above those required by the flight control system. This required structural modifications and material changes. To confirm their predictions, the project initiated several vibration tests which VAB engineers helped to design. They also analyzed the results which convinced them that they were correct and that their suggested design changes would work. Data gathered from the first failed flight as well as from the

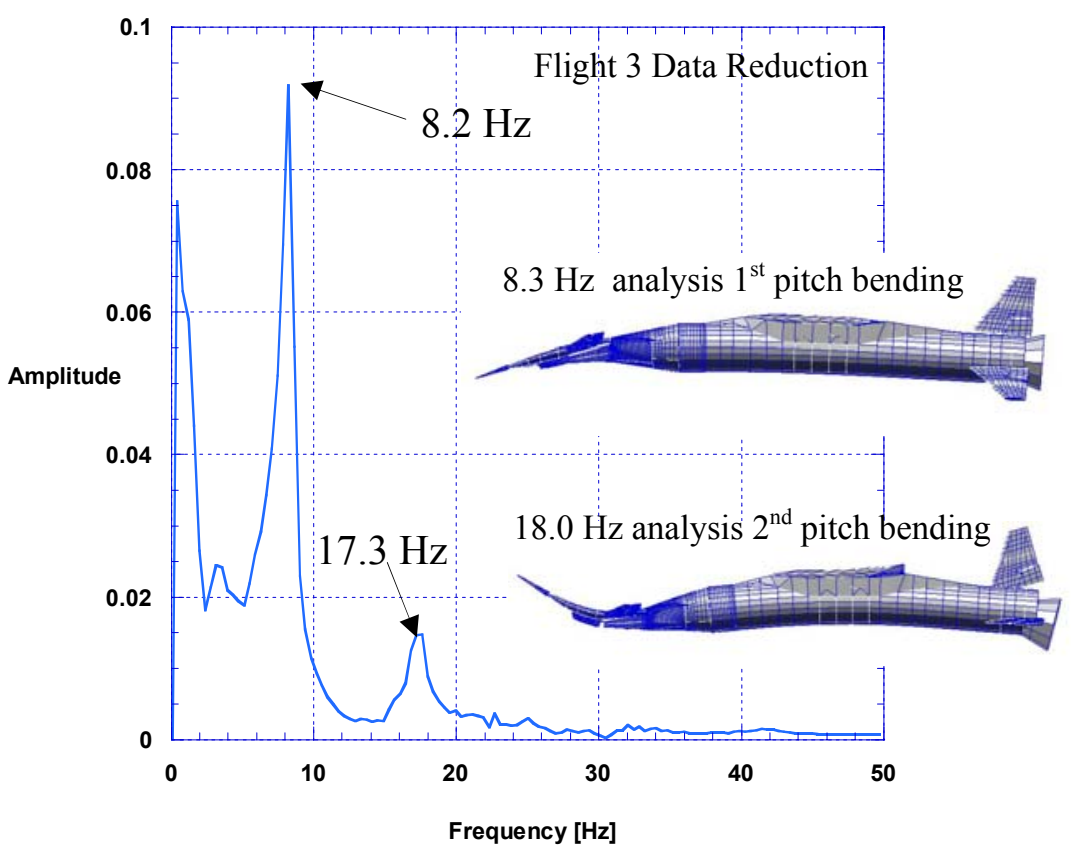

Figure 15. Frequency content for Flight 3 Z-acceleration. second and third successful flights ultimately proved that their analysis was accurate. Figure 15 shows the pitch frequency content for the Mach 10 flight. As shown, a first mode bending frequency of $8.2 \mathrm{~Hz}$ was seen in 
flight, while VAB engineers predicted $8.3 \mathrm{~Hz}$. Similar results are shown for the second pitch bending mode. VAB engineers predicted a conservative $9.5 \mathrm{~Hz}$ for the first lateral bending mode for Flight 3. Data from the accelerometers indicated a $10.2 \mathrm{~Hz}$ mode. Comparisons were similar for both flight attempts at Mach 7.

For the Mach 10 flight, the HXLV design was capable of achieving the Mach 10 test condition with little margin. As development progressed, it became clear that the vehicle would not be able to achieve the Mach 10 test goal. Engineers were required to find avenues for weight reduction to increase the scramjet test Mach number without adversely affecting the HXLV stiffness and strength in order to continue to meet the structural frequency requirements ${ }^{16}$. The Mach 10 design weighed in about 200 pounds above the target stack weight of 37,300 pounds. The options for HXLV weight reduction were limited. Any weight reduction for the booster would involve extensive analysis, design, testing, and qualification efforts. The research vehicle had a 900 pound tungsten ballast in the nose, but the HXRV was not a candidate for significant weight removal because of stability and control concerns during separation and free flight. Weight reduction efforts therefore centered on the adapter structure which supports the research vehicle and provides a smooth aerodynamic transition between the lifting-body research vehicle and the cylindrical booster motor casing. The adapter was a stiffened-skin structure consisting of a jaw and mid and aft sections which were composed of a system of panels, beams and ring frames. As VAB engineers analyzed the problem, they found that the beams and frames actually form a stable structural system without the panels. Removing this redundancy provided a means of reducing weight without a significant decrease in stiffness. Changing the adapter panels from their original stainless steel to aluminum resulted in a weight savings of $420 \mathrm{lbs}$. An additional $150 \mathrm{lbs}$ of weight was saved by removing obsolete systems and mechanisms related to a previous separation design where the jaw supporting the HXRV would actually swing away during separation. The total weight reduction attained resulted in an increase to the HXRV test Mach number of about 0.35 Mach.

VAB structural engineers were involved in analyzing and testing the roll inertia of the $\mathrm{HXRV}^{17}$ (a quantity critical to a successful stage separation event from the GN\&C perspective) as well as examining the impact of increased normal and axial accelerations on key structural components for the Mach 10 mission $^{18}$. The accelerations experienced during boost for Flight 3 were substantially higher than either Flight 2 or Flight 1. Structural components and joints for the HXRV and adapter were evaluated for these higher loads. Trajectory parameters were used to build timedependent load cases from inertial, aero, weight, and thrust forces. Inertial loads and weights were based on a breakdown of the HXLV into fifty-two components. Timedependent aerodynamic loads were based on computational fluid dynamic solutions at five time points along the trajectory path. The aero surface loads model consisted of

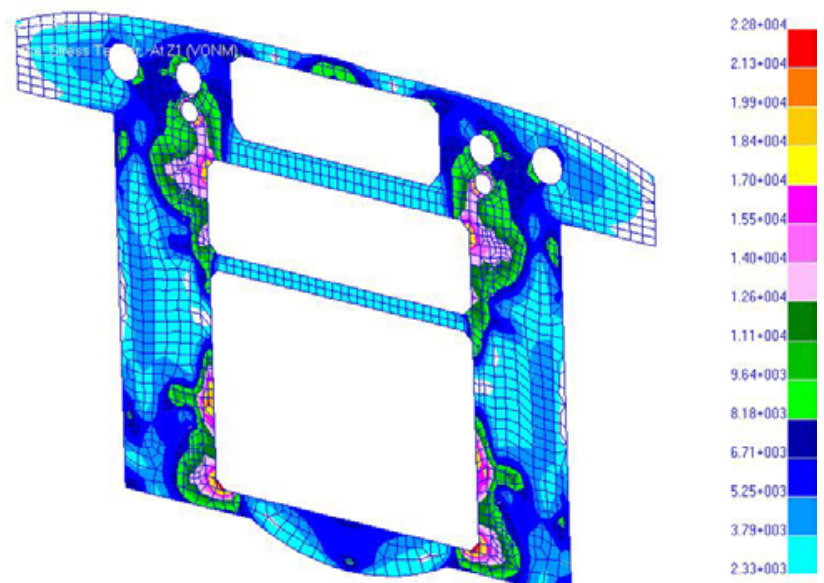

Figure 16. Von Mises Stresses for the adapter station 144 bulkhead at pull-up (inertial loads only). thirty-five components across the research vehicle, adapter, and booster. Internal forces were calculated using applied loads and the equations for dynamic equilibrium. Comparisons were 
made between internal forces based on combined aero and mass loads and mass loads only. Figure 16 shows the Von Mises Stresses for the adapter station 144 bulkhead at the pull-up condition during boost. Reaction, shear, axial force, and bending moment were used to estimate margins of safety for structural components and joints. Margins of safety were generated for major HXRV and adapter structural items and ultimately, no negative margins of safety were found.

\section{Trajectory, GNC and Flight Loads}

In addition to supporting the stage separation activity, VAB's flight mechanics experts helped develop the reference vehicle trajectories for the HXRV and HXLV and were responsible for setting the target stage separation conditions, derived from analyses, which provided the best chance for mission success while balancing thermal, weight, stability, controllability, and other issues $^{19}$. VAB engineers ran thousands of simulations to evaluate system uncertainty, expected performance, and sensitivity while also suggesting changes to both the research vehicle and launch vehicle guidance routines which were ultimately incorporated into the flight systems. Using these simulations, VAB's engineers also helped develop the expected flight envelope and ultimately the thermal and structural design loads to which the vehicle was designed and built ${ }^{20}$.

For the Mach 10 flight, VAB engineers developed a unique guidance scheme for the HXLV that significantly reduced the dynamic pressure dispersion expected during boost, which in turn would reduce the dispersion in aerodynamic heating (as heating is proportional to dynamic pressure) ${ }^{21}$. This scheme involved switching the method by which reference trajectory information was stored in the flight computer and reported to guidance during the flight. The standard guidance approach for the HXLV stored all information as a function of flight time, which would result in an expected range of dynamic pressure profiles like that shown in Figure 17. $\mathrm{VAB}$ engineers discovered that if the reference data were stored as a function of flight velocity, reduced dispersions like those shown in Figure 18 would result. Ultimately, this recommendation was implemented and flown on the Mach $10 \mathrm{HXLV}$.

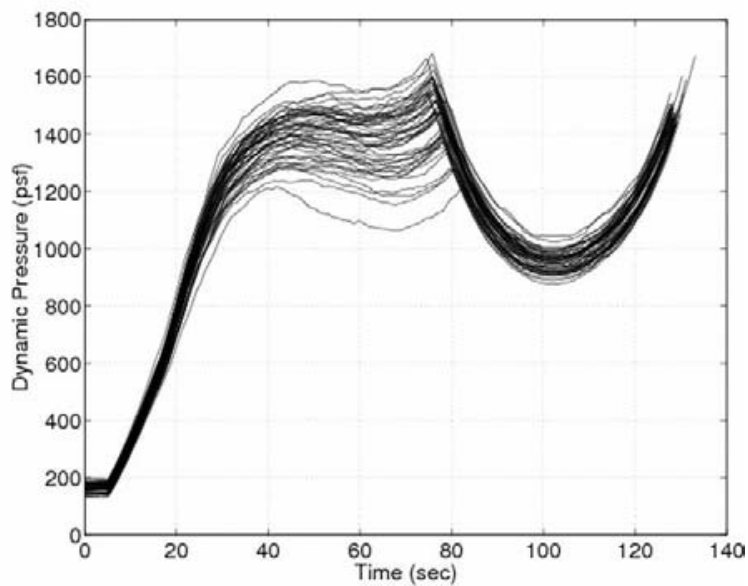

Figure 17. Dynamic pressure time histories for a sampling of Monte Carlo cases for the Mach 10 flight using time-based reference information.

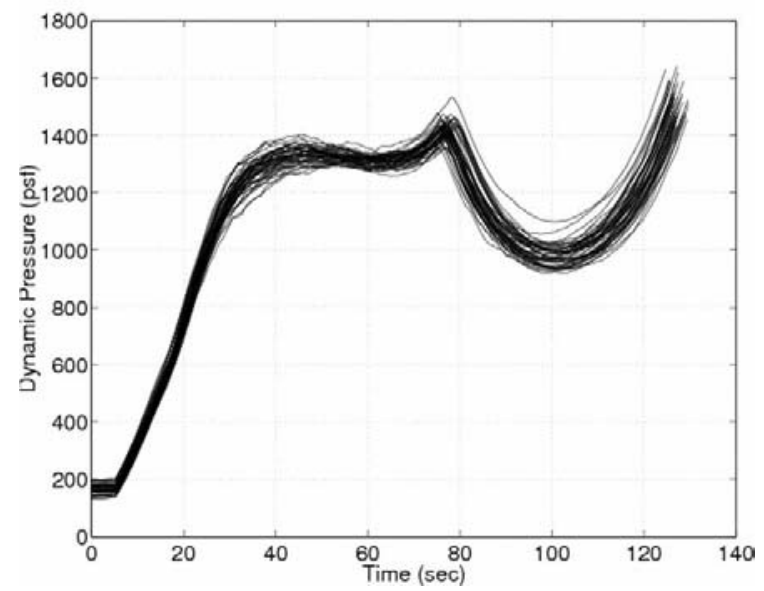

Figure 18. Dynamic pressure time histories for a sampling of Monte Carlo cases for the Mach 10 flight using velocity-based reference information.

Also for the Mach 10 flight, VAB engineers were asked to provide an updated descent trajectory for the HXRV. Performance of the guidance system on the descent of Flight 2, while adequate, was less than desirable. A closer look at Flight 2 data revealed that altitude tracked the 
reference profile until approximately 350 seconds after separation. At that point (roughtly 60,000 $\mathrm{ft}$ altitude), there was a discontinuity in the reference altitude due to a switch in the polynomial used to generate the reference trajectory. The HXRV was unable to follow the second descent polynomial and the trajectory fell below the reference. Eventually, the dynamic pressure approached a lower limit set in guidance, and the system responded by putting the HXRV into a dive. Flight path angle decreased substantially once this event occurred as the HXRV tried to maintain dynamic pressure above the guidance limit. For the Mach 10 flight, VAB engineers redesigned the descent trajectory based upon updated scramjet test conditions while keeping in mind angle of attack constraints (for roll stability concerns) and dynamic pressure limits. They developed updated polynomials to model the new reference trajectory with breakpoints and switching that matched the previous flight. This allowed the new model to be loaded into the flight software with just a change of coefficients and no software structural changes required. Figure 19 shows the improved descent performance for the Mach 10 flight, as the HXRV was able to follow the reference trajectory very closely. This, along with improved methods to calculate the splash point, allowed much improved targeting of the final entry point of the HXRV into the ocean.

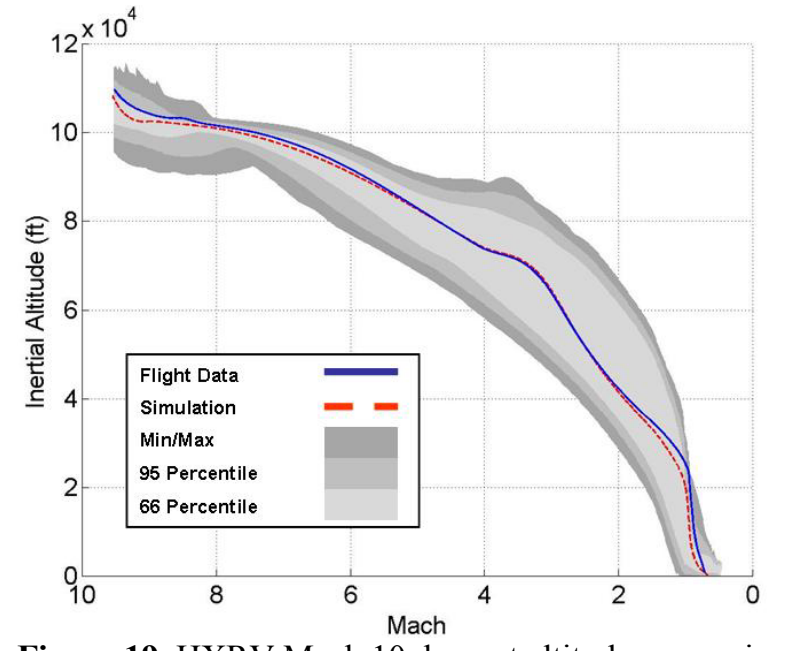

Figure 19. HXRV Mach 10 descent altitude comparison

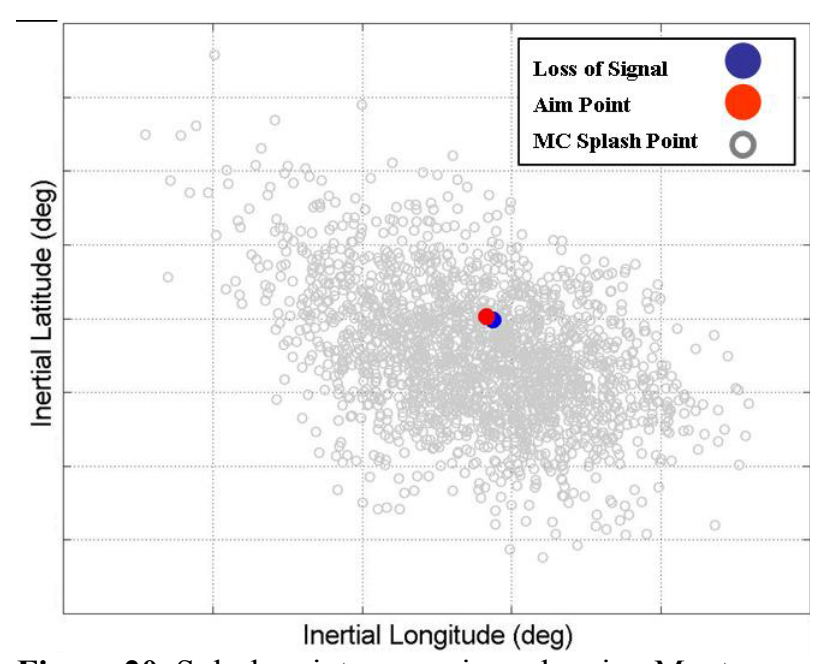

Figure 20. Splash point comparison showing Monte Carlo data, aim point and location of loss of signal.

\section{Return to Flight, Day of Flight, and Post Flight}

In addition to the involvement mentioned above, engineers from SACD supported real time assessment of flight performance for all three flight tests using previously calculated predictions. After the first flight mishap, members of SACD were involved in nearly all phases of the Return to Flight (RTF) effort ${ }^{22}$. Because of their expertise, additional members of SACD who were not directly involved in the program prior to the mishap, were asked to independently review models, data, results, and methodologies to help to determine the cause of the first flight accident. Since the second and third flights, both of which were completely successful, members of SACD continue to be involved in analyzing the plethora of data mined by each record breaking flight. VAB engineers helped to develop the Best Estimated Trajectory (BET) data for each of the flights ${ }^{23,24}$. This information serves as the official flight performance for the program upon which all analyses are performed. 


\section{Summary}

The Systems Analysis and Concepts Directorate (SACD) at NASA's Langley Research Center played a major role in the integrated team providing critical support, analysis, and leadership to the Hyper-X Program throughout the program's entire life and were key to its ultimate success. Engineers from VAB led the aerodynamic database development, the propulsion database development, and the stage separation analysis and database development effort. Others played major roles in structures, aerothermal, GN\&C, trajectory analysis and flight simulation, as well as providing CFD support for aero, propulsion, and aerothermal analysis. They were involved in all stages and aspects of the program, from conceptual design prior to contract award, through preliminary design, hardware development and system verification, flight support, and post flight analysis for each of the three flights.

\section{Acknowledgements}

The authors would like to acknowledge those individuals, both current and former members of SACD, whose contributions to the success of the Hyper-X Program have been described above: Vince Rausch, Walt Engelund, Chuck Leonard, Frank Vause, Paul Tartabini, Shelly Ferlemann, Glenn Hrinda, Lawrence Taylor, Glenn Bobskill, Kathryn Wurster, James L. Hunt, John W. Paulson Jr., Dennis Petley, Mary K. Lockwood, Richard W. Powell, Scott A. Striepe, Eric M. Queen, and Behzad Raiszadeh.

\section{References}

\footnotetext{
${ }^{1}$ Hyper-X Program Status; AIAA-2001-1910; McClinton, C.R., Rausch, V.L., Sitz, J., and Reukauf, P.; AIAA 10 ${ }^{\text {th }}$ International Space Planes and Hypersonic Systems and Technologies Conference, Kyoto, Japan, 24-27 April 2001.

${ }^{2}$ Conceptual Design of a Mach 10 Global Reach Reconnaissance Aircraft; AIAA-1996-2894; Bogar, T.J, Eiswirth, E.A., Couch, L.M., Hunt, J.L., and McClinton, C.R.; 32 ${ }^{\text {nd }}$ AIAA Joint Propulsion Conference, July, 1996.

${ }^{3}$ Airbreathing Hypersonic Systems Focus at NASA Langley Research Center; Hunt, J.L. and Rausch, V.L.; AIAA1998-1641; 1998.

${ }^{4}$ The Role of Formal Experiment Design in Hypersonic Flight System Technology Development; AIAA-2002-0543; McClinton, C.R., Ferlemann, S.M., Rock, K.E., and Ferlemann, P.G.; $40^{\text {th }}$ AIAA Aerospace Sciences Meeting and Exhibit, Reno, NV; January, 2002.

${ }^{5}$ Hyper-X Mach 7 Scramjet Design, Ground Test and Flight Results; AIAA-2005-3322; Ferlemann, S.M., McClinton, C.R., Rock, K.E., and Voland, R.T.; $13^{\text {th }}$ AIAA/CIRA International Spaceplanes and Hypersonic Systems and Technologies Conference, Capua, Italy; 2005.

${ }^{6}$ Propulsion Predictions for the Hyper-X Flight Test; Ferlemann, S.M., Jentink, T.N., Robinson, J.S., Bittner, R.D. and Pinckney,S.Z.; $36^{\text {th }}$ JANNAF CS/APS/PSHS Joint Meeting, Cocoa Beach, FL; October 18-22, 1999.

${ }^{7}$ Hyper-X Research Vehicle (HXRV) Experimental Aerodynamics Test Program Overview; AIAA-2000-4011; Holland, S.D., Woods, W.C., and Engelund, W.C.; AIAA 18th Applied Aeronautics Conference, Denver, Colorado, 14-17 August, 2000.

${ }^{8}$ Aerodynamic Database Development for the Hyper-X Airframe Integrated Scramjet Propulsion Experiments; AIAA-2000-4006; Engelund, W.C., Holland, S.D., Cockrell, C.E.Jr., and Bittner, R.D.; 2000.

${ }^{9}$ Hyper-X Wind Tunnel Program; AIAA-1998-553; McClinton, C.R., Holland, S.D., Rock, K.E., Engelund, W.C., Voland, R.T., Huebner, L.D., and Rogers, R.C.; 1998.

${ }^{10}$ Wind Tunnel Testing, Flight Scaling and Flight Validation with Hyper-X; AIAA-1998-2866; McClinton, C.R., Voland, R.T., Holland, S.D., Engelund, W.C., White, J.T., and Pahle, J.W.; 1998.

${ }^{11}$ Hyper-X Hot Structures Design and Comparison with Flight Data; AIAA 2005-3438; Leonard, C.P., Amundsen, R.M., and Bruce, W.E.; $13^{\text {th }}$ AIAA/CIRA International Spaceplanes and Hypersonic Systems and Technologies Conference, Capua, Italy; 2005.
} 
${ }^{12}$ Hyper-X Stage Separation - Simulation Development and Results AIAA 2001-1802; Reubush, D.E., Martin, J.G., Robinson, J.S., Bose, D.M. and Strovers, B.K.; $10^{\text {th }}$ International SpacePlanes and Hypersonic Systems and Technologies Conference, Kyoto, Japan; April 24-27, 2001.

${ }^{13}$ Hyper-X Stage Separation Trajectory Validation Studies; AIAA-2003-5819; Tartabini, P.V., Bose, D.M., McMinn, J.D., Martin, J.G., and Strovers, B.K.; AIAA Modeling and Simulation Technologies Conference and Exhibit, Austin, Texas, 11-14 August 2003.

${ }^{14}$ Mach 10 Stage Separation Analysis for the X43-A; AIAA-2006-1038; Tartabini, P.V., Bose, D.M., Thornblom, M.N., Lien, J.P., and Martin, J.G.; $44^{\text {th }}$ AIAA Aerospace Sciences Meeting and Exhibit, Reno, Nevada, 9 - 12 January 2006.

${ }^{15}$ Dynamic Analysis for the Hyper-X Short-Stack Modal Testing Program; Vause, R.F., and Hrinda, G.A.; $35^{\text {th }}$ JANNAF CS/APS/PSHS Joint Meeting, Tucson, AZ; December 7-11, 1998.

${ }^{16}$ Weight Reduction Studies for the X-43A Mach 10 Vehicle; Vause, R.F., Moore, D.F., Risner, N., and Lundstrom, P.; $40^{\text {th }}$ JANNAF CS/APS/PSHS/MSS Joint Meeting, Charleston, S.C., June 13-16, 2005.

${ }^{17}$ Roll Inertia Testing and Analysis for the X-43A Research Vehicle; Vause, R.F., and Schuster, L.S.; $40^{\text {th }}$ JANNAF CS/APS/PSHS/MSS Joint Meeting, Charleston, S.C., June 13-16, 2005.

${ }^{18}$ Launch Vehicle Internal Forces During Boost for the X-43A Mach 10 Flight; Vause, R.F., Leonard, C.P., Robinson, J.S., Moore, D.F., and Armand, S.C.; $40^{\text {th }}$ JANNAF CS/APS/PSHS/MSS Joint Meeting, Charleston, S.C., June 13-16, 2005.

${ }^{19}$ Experiment Design Issues for the Hyper-X; Diskin, G.S., Voland, R.T., Tartabini, P.V. and Robinson, J.S.; presented at the $34^{\text {th }}$ JANNAF CS/APS/PSHS Joint Meeting, West Palm Beach, FL; October 27-31, 1997.

${ }^{20}$ Development of Design Loads for the Hyper-X Vehicles (ITAR) Moses, P.L. and Robinson, J.S.; $35^{\text {th }}$ JANNAF CS/APS/PSHS Joint Meeting, Tucson, AZ; December 7-11, 1998.

${ }^{21}$ Hyper-X Mach 10 Trajectory Development and Monte Carlo Analysis; Robinson, J.S.; $36^{\text {th }}$ JANNAF CS/APS/PSHS Joint Meeting, Cocoa Beach, FL; October 18-22, 1999.

${ }^{22}$ Review of X-43A Return to Flight Activities and Current Status; AIAA2003-7085; Reubush, D.E., Nguyen, L.T., and Rausch, V.L.; $12^{\text {th }}$ AIAA International Space Planes and Hypersonic Systems and Technologies Conference, Norfolk, Virginia, 15 - 19 December 2003.

${ }^{23}$ Hyper-X Post-Flight Trajectory Reconstruction; AIAA-2004-4829; Karlgaard, C.D., Tartabini, P.V., Blanchard, R.C., Kirsch, M., and Toniolo, M.D.; AIAA Atmospheric Flight Mechanics Conference and Exhibit, Providence, Rhode Island, 16 - 19 August 2004.

${ }^{24}$ Hyper-X Mach 10 Trajectory Reconstruction; AIAA-2005-5920; Karlgaard, C.D., Martin, J.G., Tartabini, P.V., and Thornblom, M.N.; AIAA Atmospheric Flight Mechanics Conference and Exhibit, San Francisco, California, 15 - 18 August 2005. 